\title{
GOBERNANZA DEL EMPRENDIMIENTO SOCIAL RESPONSABLE
}

\author{
Óscar Coronado Rincón \\ Javier Carreón Guillén \\ Celia Yaneth Quiroz Campas \\ Eyder Bolivas Mojica \\ Cruz García Lirios
}

\section{Academic Transdiciplinary Network, México}

https://doi.org/10.33676/EMUI_nomads.57.03

\begin{abstract}
Resumen.- Se incluye una revisión y discusión del emprendimiento como una cuestión social. Se realizó una revisión sistemática documental con una selección de fuentes indexadas a repositorios internacionales, considerando el periodo de 2010 a 2019, así como el tipo de literatura clasificada según el efecto de las políticas sectoriales de fomento empresarial y micro financiamiento en pequeñas y medianas empresas. Se estableció la teoría y los estudios concernientes, así como una discusión de los resultados reportados por el estado del conocimiento, advirtiéndose la necesidad de ampliar la búsqueda de información en otros repositorios.

Palabras clave: Gobernanza, emprendimiento, conocimiento, capital, agenda

Governance of social entrepreneurship: Review of literature for the discussion of the state of knowledge
\end{abstract}

Abstract.- A review and discussion of entrepreneurship is included as a social issue. A systematic documentary review was carried out with a selection of sources indexed to international repositories, considering the period from 2010 to 2019, as well as the type of literature classified according to the effect of sectoral policies of business development and micro financing in small and medium enterprises. The theory and the relevant studies were established, as well as a discussion of the results reported by the state of knowledge, noting the need to expand the search for information in other repositories.

Keywords: Governance, entrepreneurship, knowledge, capital, agenda

\section{Introducción}

El Emprendedurismo supone representaciones, habitus, campos y capitales en torno a la producción, comercialización y formación empresarial. En cierto sentido, la objetivación y anclaje, procesos esenciales de las representaciones sociales, explican la trasformación de saberes y conocimientos en sentido común, más precisamente, heurísticos desde los cuales la lógica de oferta y demanda se desvanece en afectos o sentimientos acerca de orientar tiempo y dinero a la producción de café (Villegas, Sánchez, Espinoza, García y Quintero, 2019). 
Empero, no sólo los conocimientos son trastocados por fuerzas emprendedoras, sino además ajustados a la dinámica local ecoturista. En este sentido, el discurso entre otros elementos, es el medio para construir predisposiciones en torno a la caficultura.

Es así como a través de las representaciones sociales, la caficultura se transforma en habitus discursivos desde los que se sustentan las convenciones locales en referencia a las convenciones globales ya que las microempresas al estar vinculadas con trasnacionales adoptan formas organizativas y discursos para fomentar el espíritu emprendedor en habitantes de "pueblos mágicos" como en el caso de la región huasteca en Xilitla, San Luis Potosí, México (Mejia, Carreón, García, Quezada, Martínez, López, Hernández y Morales, 2019).

Se trata de un proceso en el que los símbolos, significados y sentidos son categorizados en imágenes que impactan la interpretación y acción personal, aunque tal proceso se disemina a los grupos y organizaciones relativas al café. Esto hace posible la distinción social de un sector emprendedor en alusión a la comunidad, pero incluso en referencia a los demás grupos agricultores de la región huasteca.

A nivel discursivo, no sólo es posible diferenciar los símbolos o significados en sus ámbitos temporales o espaciales, sino además anticipar la diversidad de expectativas que se generan luego de que una actividad empresarial se ha erigido como un sello distintivo de una comunidad en clara alusión a la industria, el comercio, el turismo o las pobreza, marginación, vulnerabilidad o exclusión. Tales dimensiones se condensan en propensión o aversión al futuro ya que mientras las representaciones sociales se conectan con el pasado y el futuro, generan predisposiciones de riesgo en torno a los cuales se planifica una siembra y cosecha. Es decir, la representación de la caficultura parece circunscribir a preferencias, acciones, sentimientos o pensamientos los cuales constituyen discursos que delimitan campos de expectativas y generan relaciones de cooperación y confianza (Rosas, Gómez y García, 2019).

¿Qué representaciones, habitus, campos, capitales en torno a la caficultura inciden en qué capacidades emprendedoras y en qué contextos de migración o comercio en Xilitla?

Tal cuestión implica cinco marcos teóricos explicativos de la imbricación de la caficultura en los discursos de productores y comerciantes. La Teoría de Representaciones Sociales al ser un proceso de comunicación de innovaciones respecto a la caficultura, se infiltra en los símbolos y significados que construyen los microempresarios. Una vez que estos se han infiltrado en imágenes y palabras, ahora son recuperados como repertorio de conocimientos respecto a la siempre o cosecha de café. 
Si una representación vincula a la caficultura con otros menesteres personales o comunitarios, entonces supone disposiciones que facilitan la objetivación o el anclaje de la información relativa a la siembra, cosecha, clima, plagas, precios y cotizaciones. Si tales disposiciones han sido transferidas de generación en generación entonces un estudio longitudinal daría cuenta de las representaciones, objetivación y anclaje, así como de sus habitus, heredado o adquirido, a lo largo de un periodo relativamente transitorio en el que la comunidad pasó de ser migrante a microempresaria (García, Quintero, Carreón, Rincón, Sánchez, Fierro, 2019).

Es así como la Teoría del Habitus Discursivo enfoca los esfuerzos de explicación en aquellos símbolos de los que pueden derivarse símbolos, agruparse y resignificarse evidenciando al mismo tiempo un modo de pensar, actuar y sentir que distinguiría a Xilitla de otros pueblos originarios 0 mágicos dedicados a la caficultura.

Para los propósitos del presente estudio, diferenciar a las comunidades es el primer eslabón para inferir el proceso por medio del cual un grupo de migrantes se transformaron en microempresarios. En tal sentido, la Teoría de los Campos de Poder sostiene que los conflictos derivados de la distribución asimétrica de los insumos para la caficultura es el motor de los cambios que se avecinan en la producción y comercialización del café en la microrregión.

Sin embargo, tal trasformación parece ser más discursiva ya que mientras los migrantes de Xilitla retornan, grupos de comerciantes se dan la tarea de emprender nuevos proyectos y planes de negocios que implican la difusión del pueblo como un lugar de turismo y recreación más que de producción y venta de café. A nivel de los símbolos, es necesario comprender las relaciones discursivas entre quienes generan empleos y quienes los diversifican con la difusión de innovaciones comunitarias tales como ecoturismo, producción orgánica, artesanía y comida típica.

Tal proceso de diversificación e imbricación de la caficultura está centrado en la formación de redes colaborativas ya no sólo discursas. Se trata de procesos de confianza en los que la cooperación entre las familias de caficultores hace factible su análisis como capitales sociales en las que el conocimiento ya no es un asunto de gestión, sino de representación, habitus y empoderamiento.

De este modo, Xilitla se asume como una entidad próspera en lo económico porque está anclada en discursos que versan sobre el emprendimiento, comercio y progreso. Es decir, cuando menos la comunidad ya no presenta síntomas de empobrecimiento discursivo o económico. Las personas que viven en ésta micro región se asumen como responsables de su propio destino y actúan en consecuencia, llevan a cabo acciones motivados por 
la diferenciación social que supone ser migrante, comerciante, caficultor o microempresario.

Sin embargo, el proceso estaría incompleto si no reconociéramos las oportunidades en consonancia con las capacidades y responsabilidades de los habitantes de Xilitla para con sus generaciones futuras y demás redes de capital social que actúan a favor del progreso de la comunidad o por lo menos el distanciamiento con la pobreza. La Teoría de las Capacidades Económicas en consonancia con las libertades de elección para el revestimiento del tejido social en cuanto a empleo, salud y educación, asume que los individuos son agentes de conocimiento y gestión cuyas capacidades permiten la diseminación de responsabilidades para con los grupos en los que están inmersos.

Precisamente, es en este punto donde los símbolos y los significados respecto a la caficultura se vinculan con escenarios de colaboración y transferencia de saberes que les permiten a los comerciantes adentrarse en un mercado local. Es aquí donde parece emerger el conocimiento que posibilita la diferenciación de la caficultura en siembra, cosecha, refinamiento, empaquetamiento, logística, distribución, preparación y venta. Las nuevas generaciones de cafricultores no sólo han objetivado o anclado el conocimiento, sino además lo han asumido como parte de sus estilos de vida y modos discursivos.

Frente a las problemáticas ambientales de sequías o inundaciones, las redes de capitales sociales en Xilitla responden con organización del cultivo en etapas diversificadas, pero confinadas al logro de metas que les garanticen el ciclo productivo. Más aún, el proceso productivo es complementado con la gestión y promoción de la caficultura en otras localidades de la región y más allá de la misma como entidad turística. Esta es la clave del éxito económico y la prosperidad en Xilitla de la que las remesas siguen siendo parte fundamental de la dinámica económica, pero es el capital simbólico el que impulsa las relaciones sociales, políticas y económicas. La cultura del emprendimiento o el espíritu emprendedor de Xilitla socava la pobreza e incentiva las capacidades empresariales y laborales para estabilizar las representaciones, habitus, campos y capitales relativos a la caficultura.

\section{Teoría de la Gobernanza del Emprendimiento Social}

Las representaciones son innovaciones discursivas desde las que el conocimiento científico se disemina en el sentido común y el pensamiento social, aunque ello no sólo es exclusivo de la ciencia, el arte o la cultura en general ya que los símbolos por descubrir o inventar son proclives también a su transformación en interpretaciones de la realidad y más propiamente sentidos discursivos (Caykoylu, Egri, Havlovic \& Bradley, 2011). Empero, las 
representaciones sociales al ser comunicativas se alejan de la cognición individual y se aproximan a las relaciones asimétricas de los grupos. Una vez que la información científica está asequible, los grupos se encargan de socializar sus contenidos. Para tal fin será necesaria una diferenciación entre los grupos a fin de establecer los conflictos que los lleven a anticipar cambios. Los grupos se dividen en minorías y mayorías en torno a información circundante que les permite representar prototipos de comportamiento para construirse una identidad (Fuentes y Sánchez, 2010). En tal escenario, la percepción de justicia disemina la legitimación de las decisiones. Empero, la transferencia de información pública deviene en su incorporación al repertorio de conocimientos personales (Figeiredo, Grau, Gil \& García, 2012). Este es así porque la información es un medio de difusión de las relaciones asimétricas entre los grupos e individuos, pero suponer que la dinámica grupal está imbricada al igual que la individual en un objeto de representación que cuando no es social es cultural o por lo menos confextual implica una reducción de los símbolos a expectativas, habilidades o actitudes (Mendoza, Orgambídez \& Carrasco, 2010).

Más bien, las representaciones sociales son interpretaciones observables, pero ello no sugiere que estas puedan ser síntomas de percepciones, creencias, motivos o conocimientos ya que son convenciones 0 discrepancias, pero no pueden ser indicadores de procesos individuales (Gargallo, 2010).

Es por ello que las representaciones sociales facilitan e inhiben la inserción de símbolos en el repertorio cultural individual, pero sobre todo en las imágenes que compartimos o queremos disuadir. Se trata de un núcleo central figurativo y un conjunto periférico de actos concretos en los que los componentes ideológicos son envueltos por una periferia emergente de símbolos comunes y convencionales (Morales, Ariza \& Muñiz, 2012).

Al proceso que va de lo abstracto en concreto se le conoce como objetivación y a los símbolos que se incorporan en el repertorio discursivo se le llama anclaje, empero, al ser la representación una organización de los símbolos compartidos por un grupo, la objetivación confina tales símbolos a palabras que tendrán un significado más próximo a la experiencia y estilo de vida del grupo que la adopta, o bien, le asigna imágenes a tales aseveraciones de conocimiento, aunque termina incorporándose como señales perceptuales, rasgos actitudinales o síntomas de disposiciones (Galindo y Echavarría, 2011).

En el caso del anclaje, se trata de un proceso complementario de incorporación de símbolos al archivo perceptual o actitudinal del individuo, pero el anclaje supone una defensa mediante esos mismos símbolos que en el pasado fueron incorporados y que ahora compiten por el control de las decisiones y acciones personales (Gaxiola, Frías, Hurtado, Salcido y Figueroa, 
2011 ). En ese sentido, concreción, regulación y defensa se constituyen como elementos fundamentales de las representaciones sociales, aunque ocurran en la mente humana, en realidad son convenciones por no decir construcciones de la realidad que al ser compartidas por un grupo organizan no sólo a las personas, sino a su entorno. Es decir, las representaciones sociales son organizaciones de la realidad que impacta al individuo y al grupo, pero es una obra social que por ser invisible pensamos que se transforma en imágenes, pero sólo basta con cambiar de contexto para dar cuenta de la diversidad de representaciones.

De este modo, en un contexto en el que los símbolos están orientados por representaciones sociales y los significados por sus procesos de objetivación y anclaje, los sentidos o direcciones de símbolos y significados son orientados por la defensa de las representaciones que ante conflictos y cambios repercuten en su centralidad porque la periferia es tan abrupta que devela una interrelación con la centralidad y ello hace suponer que las representaciones sociales en realidad son interpretaciones más que comunicación, cognición o persuasión, son información que puede ser sesgada para transformar usos y costumbres (Vargas y Arenas, 2012).

En el caso de la migración y el emprendimiento sus representaciones sociales parecen estar confinados a una dinámica de corto plazo ya que los costos y beneficios son quienes más modificarían la centralidad de la representación social. Es decir, ante préstamos, créditos, financiamientos, inversiones y demás apoyos económicos, los migrantes, comerciantes y caficultores están expuestos a tomar sus decisiones ya no a partir de su sentido común, sino a partir del balance entre sus ingresos y egresos (Vargas y Mota, 2013).

De acuerdo con el estado del conocimiento, migración y emprendimiento son procesos psicológicos y sociales explicados desde la representación social, clima organizacional, confianza (Velasco, Spencer y Navarra, 2011), liderazgo (Anwar y Norulkamar, 2012), compromiso (Danes y Juyoung, 2013), capital, habitus y satisfacción.

A partir del estado de la cuestión es posible anticipar un modelo reflejante para ilustrar las representaciones sociales centrales y periféricas en torno a la caficultura en Xilitla, San Luis Potosí, México. Antes bien, las representaciones sociales únicamente explican los contextos de migración y emprendimiento, pero no aclaran su permanencia. Es decir, por qué México es un país expulsor de migrantes y ahora por qué se transforma en un país de emprendedores son cuestiones que sólo pueden ser explicadas desde la Teoría del Habitus Discursivo.

El concepto de habitus alude a un conjunto de disposiciones ancladas, si se quiere relacionar con las representaciones sociales, en el núcleo o 
centralidad de un contexto (Bourdieu, 2011). En tanto sistema de disposiciones, están indicadas por asociaciones entre personas, comportamientos, sentimientos, oportunidades, capacidades, responsabilidades o libertades (Capdevielle, 2011). Sin embargo, sus síntomas psicológicos son sólo parte de dimensiones sociológicas desde las que es posible advertir diferencias entre grupos, comunidades, sociedades, culturas o generaciones (García, 2011). Se trata de relaciones entre las estructuras, creencias, normas y valores, que pueden estar en organizaciones o instituciones, pero al no ser exclusivas de tales contextos abre la posibilidad de que los habitus sean en sí mismos contextos de escenarios (Vega, Madrazo y García, 2011). En tal proceso, el habitus discursivo se enlaza con prácticas que enaltecen las diferencias entre individuos ya que pueden actuar bajo el mismo contexto, pero la significación o resignificación de espacios, objetos o personas es diferente. Esto es así porque los habitus son producto de asimetrías, discrepancias, controversias, desencuentros o tensiones que pueden ser de corta duración, aunque puedan extenderse dada la magnitud del conflicto y sobre todo, la influencia del contexto (Castro y Martins, 2010). Lo cierto es que un contexto impacta acciones, sentimientos, percepciones y pensamientos de un modo más duradero porque se infiltra en la estructura de las habilidades discursivas y al ser naturalizadas, siguiendo el discurso de las representaciones sociales, ya no sólo están en la periferia, sino se han incorporado al núcleo central. Es decir, los habitus son el resultado de la penetración del contexto en el repertorio cultural de los individuos y al haberse infiltrado en los conceptos de defensa han logrado familiarizarse con los elementos centrales (Castro, 2011).

Joignant (2012) reconoce que los habitus son, en esencia, una consecuencia del contexto en forma de esquema y organización de símbolos. Esta dualidad hace más factible reconocer la complejidad del contexto ya que los habitus son sus indicadores. Se trata de un contexto, en términos de vida humana, corto ya que son estructuras heredadas y aprendidas en los primeros años de vida. Tal proceso devela una dimensión sociohistórica del habitus y por ende otra dimensión sociopolítica consistente en la socialización de los esquemas y estructuración de las disposiciones cual si fuese un proceso dialéctico, pero no lo es porque más bien se trata de la influencia del contexto en los esquemas personales (Robles y Leso, 2012).

Al igual que las representaciones sociales que se defienden de la emergencia de otros símbolos, el habitus no reparara en contrarrestar la influencia de otros habitus mientras define las acciones a seguir según los contextos a disuadir puesto que nuevos acontecimientos implicarían una diversidad de respuestas, pero tales recursos son más bien homogéneos gracias a que cada persona incorporó un sistema de símbolos, significados y sentidos que los diferencian de otras personas o de sí mismas bajo 
circunstancias similares o diametralmente diferentes (Basta, Cavalleri, Fink, López, Maiola, Stancanelli y Vdovsov, 2012).

En suma, los habitus provienen del pasado ubicado en la infancia, pero también al ser adquirido y no sólo heredado, supone disposiciones emergentes que indican la penetración del contexto en la estructura de disposiciones (Martínez, 2013).

En el caso de la migración y el emprendimiento, los habitus explican el proceso por medio del cual una sociedad transita de expulsores a comerciantes (Chinchilla y Cruz, 2010). Esto desde luego, va más allá de la influencia del contexto en las comunidades o individuos, supone la incidencia de políticas públicas relativas al turismo ya que la comunidad huasteca de Xilitla obtiene sus ingresos a partir de la promoción de su espacio ecoturista, zonas montañosas y boscosas así como sus usos y costumbres cafetaleros. De este modo, los habitus del pasado comunitario explican la migración ya que en su afán de construir un patrimonio los residentes de Xilitla tuvieron que buscar empleo fuera de su territorio. Una vez edificado un patrimonio, los exmigrantes retornaron a su comunidad para establecer los discursos adquiridos en el exterior y que es posible identificar como un proceso de emprendimiento si se asume que para tal propósito se generó un clima de confianza, compromiso y satisfacción. Es decir, las nuevas generaciones de emprendedores son el resultado de una generación que heredó un habitus migratorio y/o transformó en un habitud emprendedor, pero tal proceso debió ocurrir en un contexto en el que las políticas de fomento empresarial estratégicamente se orientaron al turismo y sus derivados. Se cumple así la premisa sociohistórica del habitus según la cual una coyuntura es el resultado de una estructura, aunque no del todo influida, si ha sido trastocada en sus fundamentos ya que la comunidad de Xilitla ahora es emprendedora. La repavimentación de sus calles, la remodelación de sus edificaciones, la reubicación de sus residuos, el financiamiento de su comercio y la inversión en infraestructura hotelera, restaurantera y carretera hacen suponer que la comunidad apuesta por el turismo como alternativa de progreso y prosperidad, pero existe un sector cafetalero que ha sabido insertarse en el habitus migrante y ahora en la nueva dinámica emprendedora ya que emplea a otros trabajadores de pueblos circundantes y comercializa con otros grupos de caficultores de la región huasteca.

Si bien es cierto que el habitus migrante y empresarial son discursos relativos a la búsqueda de oportunidades, capacidades y responsabilidades, llama la atención que en el caso del habitus migrante las emociones predominan sobre las acciones o deliberaciones que corresponden al habitus emprendedor (Vargas, 2011). Es decir, la diferenciación entre uno y otro habitus estriba en que la situación económica impedía la realización de 
innovaciones y orientaba las acciones a la migración mientras que en la situación actual parecen conjuntarse los factores mínimos para la realización de proyectos que son financiados por el Estado a través de la secretaria de turismo y del trabajo, pero que son aceptados y desarrollados por la comunidad (Vargas, 2013).

Empero, a la par de que se forjó un habitus emprendedor, se redistribuyeron los recursos, principalmente los discursos y sus bienes simbólicos que dieron origen a escenarios de poder sin los cuales sería imposible explicar las diferencias entre jornaleros y caficultores, autoridades y ciudadanos, políticos y comerciantes.

Un campo de poder es el equivalente a uno electromagnético, ya que denota un espacio construido por fuerzas internas en referencia a externas (Berdecia, González \& Carrasquillo, 2012). No obstante, un campo de poder es simbólico más que físico o magnético, pero funciona de un modo similar porque atrae a propios y expulsa a extraños (Díaz, 2013). Sin embargo, un campo de poder sólo refleja relaciones asimétricas respecto a bienes o capitales simbólicos que estructuran a grupos frente a conflictos que los diferencian de otras comunidades (Joignant, 2012). De este modo, los campos de poder se enlazan con representaciones y habitus al circunscribir el anclaje y defensa de símbolos, empero a diferencia de estos mismos, los campos de poder reflejan asimetrías y por ello se asumen como una causa de las representaciones y habitus.

Más que la socialización de las diferencias, los campos de poder son la interrelación de recursos o capitales que definen el poder de un grupo sobre otros similares en sus habitos o representaciones (Fortich y Moreno, 2012). En este sentido, si un campo de poder emite símbolos que serán resignificados por individuos, entonces se trata de ámbitos en los que la defensa de representaciones y habitus predomina sobre la producción de símbolos. Rivas (2012) sugiere que tales escenarios de defensa simbólica indican la actividad profesional de un grupo. Se trata de un espacio deliberado en el que la producción de símbolos esta confinada a la defensa de dicho territorio más que a su resignificación o cambio.

En el caso de la migración, un campo de poder es inferido por el discurso en torno a la travesía, la permanencia o el retorno. Es decir, los migrantes construyen símbolos para defender su estilo de vida como migrantes a diferencia de quienes residen con todos los derechos y garantías individuales. Empero, los migrantes construyen un campo de poder no para preservar sus modos de convivencia, sino para resguardarse de otros discursos que les impliquen el abandono de sus raíces y el recorte de remesas para sus familiares (Giddens, 2011). Es por ello que el monto de envíos de dinero sobrepasa otras fuentes de ingreso como el turismo, pero además la migración parece sustentarse por las redes de capital o bienes 
simbólicos que los mismos migrantes llevan consigo cada vez que relatan sus experiencias. En contraste, el espíritu emprendedor parece configurarse a partir de múltiples espacios de poder (Lanier, 2012). Cuando menos caficultores, intermediarios y vendedores construyen discursos a partir de la distribución de sus espacios interactivos. Piénsese en los caficultores que delimitan sus acciones y discursos a la siembra y cosecha, naturalmente están en desventaja con respecto a quienes gestionan sus recursos financieros, logísticos o productivos.

No obstante, un campo de poder es simbólico y como tal se entiende que los conflictos y cambios que en el ocurren también lo son. Es por ello que ante sequias e inundaciones los símbolos de poder que están en juego se refieren a pronósticos y estrategias relativos a tecnologías y gestión del conocimiento. Es decir, quien accede a información especializada tiene el control del campo simbólico de poder.

Pueden observarse como indicadores del campo de poder relativo a la migración algunos rituales vinculados con la travesía, la permanencia y el retorno. En el caso opuesto, los indicadores del emprendimiento, en tanto campo de poder, estarían concretados en los saberes y conocimientos deliberados o heurísticos, planificados o improvisados, sistemáticos 0 automáticos. Es decir, mientras los migrantes utilizan como escenarios de influencia a los afectos y emociones, los comerciantes aluden al conocimiento administrativo o jurídico para diferenciarse de otros grupos económicos con los que compiten.

Precisamente, es aquí donde la comunidad de Xilitla en referencia a otras aledañas, ha construido discursos alusivos a la generación de oportunidades y capacidades para un crecimiento responsable social y ambiental. Ello implica elementos relativos a sus bienes o capitales simbólicos.

El concepto de capital es equivalente a bienes o recursos que son utilizados para enaltecer a un individuo sobre otro respecto a libertades y oportunidades de elección (Castel y Freundlich, 2010). Sin embargo, el término es volátil ya que supone indicadores económicos, culturales, naturales o sociales. Empero, la literatura sobre el capital humano parece converger en cuanto a que se trata de valores, habilidades y conocimientos adquiridos por la formación profesional (Coronel, 2010).

Incluso los elogios son parte del capital humano ya que la motivación de talentos es un aspecto fundamental para un clima de confianza, compromiso y satisfacción (González y Pérez, 2012). En este sentido, el capital humano es discursivo, aunque tenga un contenido simbólico, opera de un modo peculiar a través de la motivación y el liderazgo (González, Sánchez y López, 2011). En principio, el capital humano supone la subsistencia, pero también la consolidación de un sistema de símbolos que 
operan a favor de una representación, habitus o campo de poder (Guillén, Lleó y Perles, 2011). En efecto, el capital humano es un instrumento de objetivación, anclaje, herencia, adquisición y construcción de escenarios de símbolos que dan poder a quienes los utiliza (Joignant, 2012).

Empero, el capital humano es un instrumento frágil ya que puede romperse si existe un intersticio de desconfianza o ausencia de compromiso (Manning, 2010). O bien, es un medio de manipulación que consiste en materializar las expectativas o consolidar las redes colaborativas desde las que se tejen representaciones, habitus y campos como discursos en torno al poder (Sen, 2011). Del mismo modo que el crédito financiero opera como respaldo de confianza y certidumbre para las relaciones comerciales, el crédito del conocimiento, valores y habilidades que se le otorga a un grupo o individuo expresa confianza en que tal persona es capaz de satisfacer una necesidad, solucionar un problema o simplemente ampliar la brecha simbólica entre grupos (Sobrados \& Fernández, 2010). Es decir, se trata de talentos humanos que pueden llegar ser líderes de opinión y movilización a favor de intereses económicos, políticos, sociales o culturales.

En el caso de la migración, el capital humano atiende a la expulsión de talentos no sólo por sus conocimientos o habilidades, sino por sus valores de honestidad como es el caso de jornaleros o cuidadoras que en el mercado son vistos como ejemplos de dedicación y esfuerzo. En el caso de las organizaciones, los valores de lealtad y compromiso son requisitos indispensables para la calidad y competitividad de las pequeñas y medianas empresas frente a la inserción de las trasnacionales en la comunidad.

Ambas dimensiones del capital humano, migratoria y empresarial parecen aproximarse dado que ambas comparten valores que hacen únicos a los migrantes y emprendedores de Xilitla con respecto a otras comunidades que vieron partir a sus jóvenes, pero no los vieron retornar, o bien, observaron como las ganancias de sus empresarios no se reinvirtieron en sus comunidades y al final quedaron abandonadas sin recursos naturales ni infraestructura para el turismo ya que sus migrantes no regresaron y pasaron de ser pueblos originarios a pueblos fantasmas sin haber sido pueblos mágicos.

Tal diferencia se explica por la generación de oportunidades no sólo de empleo, sino de vida y crecimiento personal que conlleva habilidades y responsabilidades.

Una capacidad es el resultado de libertades y oportunidades al mismo tiempo que es la causa de la generación de responsabilidades sociales y ambientales (Arnau \& Montané, 2010). En tal sentido, la Teoría de las Capacidades Económicas asume que la libertad de elección, difundida por 
políticas públicas liberales o neoliberales, es el contexto propicio para el surgimiento de oportunidades que obligarán a los individuos a perfeccionar - especializar sus conocimientos y ajustar sus habilidades a los requerimientos del mercado (Cuesta, 2012). Ello implica saberes de anticipación y comprensión de las problemáticas. Sobre todo frente a crisis, la selección de los elementos más adaptativos es menester para afrontar los retos de cambios inesperados que no suponen conflictos o diferencias entre las partes involucradas en ta competencia por los recursos (Borjas, 2010). En el caso de los grupos y sus dinámicas diferenciales internas, las capacidades son una fuente de estabilidad ya que la diversidad de oportunidades genera ideas innovadoras de las cuales la más óptima será elegida por el grupo (Long, 2013).

Ante los desafíos del entorno, los grupos buscan a toda costa solventar sus carencias mediante la mejora continua de capacidades vía el adiestramiento o entrenamiento, pero al ser un proceso externo, transforma de un modo $u$ otro la dinámica del grupo (Sen, 2011). A medida que tales respuestas a la contingencia interna proviene de diversos saberes y conocimientos, mayor es la probabilidad de que permanezcan en constante competencia para beneficio del grupo (Genesí, Romero \& Tinedo, 2011). Es así como un grupo adquiere ventajas competitivas respecto a otro similar en representación, habitus, campo o capital, pero diferente en cuanto a libertades, oportunidades, capacidades y responsabilidades (Henao \& Londoño, 2012).

Las capacidades económicas explican las diferencias grupales en una misma comunidad y la competencia por sus recursos sean financieros 0 naturales (Ríos, Téllez, y Ferrer, 2010). En el caso de la migración y el emprendimiento, las capacidades son el resultado de una serie de políticas públicas relativas a la expulsión de mano de obra barata y al fomento empresarial para el desarrollo del turismo a gran escala.

Es posible observar que las capacidades económicas migrantes obedecen a una serie de intenciones y acciones bajo riesgo frente al emprendimiento de procesos productivos, distributivos y logísticos bajo un contexto de flexibilidad. Ambas dimensiones desreguladas por el Estado y sus políticas de fomento empresarial a costa de reducir los derechos laborales. Sin embargo, el apoyo financiero supone una planificación mínima de las organizaciones siempre que se justen a los objetivos de los programas de públicos para emprendedores, microempresarios o comerciantes en torno a la caficultura. En contraste, la migración desamparada del Estado, asume comportamientos de riesgo que implican una mayor probabilidad de improvisar la práctica migrante, inserción laboral, redes de apoyo, o bien, mayores posibilidades de fraude, extorsión o robo de bienes. En este sentido, las capacidades denotan habitus de riesgo y representación de 
incertidumbre para el caso de la migración y habitus de microfinanciamiento así como representaciones de flexibilización o alianzas entre pymes y trasnacionales para el caso del espíritu empresarial.

En síntesis, ambas dimensiones, migratoria y empresarial parecen diferenciarse, pero más bien son parte de un mismo proceso que va de la exclusión a la inclusión pasando por la marginación y la vulnerabilidad de una comunidad huasteca a lo largo de dos sexenios en los que las políticas públicas contribuyeron al desarrollo del espíritu empresarial en la micro región. Son precisamente, las representaciones, habitus, campos, capitales y capacidades tos indicadores de dicho proceso que va de la migración al emprendedurismo.

\section{Estudios de la gobernanza del emprendimiento social}

El espíritu emprendedor ya sea heredado en el lugar de origen o adquirido en el lugar de estancia migrante supone un proceso que culminaría con la satisfacción de vida a medida que la remuneración se incrementa o las oportunidades se diversifican (Chiang, Méndez y Sánchez, 2010). Es decir, la satisfacción de vida parece tener un vínculo con el espíritu emprendedor en cuanto a la búsqueda de utilidad, ganancia y beneficio por una actividad sistemática y que implica un compromiso con una organización.

Es por ello que en contextos de incertidumbre el Mobbing inhibe la satisfacción de vida y resignifica el espíritu emprendedor ya que los obstáculos que representan las relaciones de tarea están socavados por las relaciones humanas (López, Vázquez y Montes, 2010). En efecto, si las relaciones entre compañeros se sobreponen a los objetivos del grupo, entonces en el espíritu emprendedor emergen dimensiones de orden resiliente en los que el individuo desarrollará estrategias de afrontamiento ante los inconvenientes de laborar bajo un clima de tensión.

En tal escenario, el espíritu emprendedor correlaciona con estilos de liderazgo transformacional en los que cada uno de sus síntomas están sustentados por acciones específicas de innovación que trastocan otros estilos correctivos, evitativos, o motivadores (Molero, Recio y Cuadrado, 2010). En este sentido, las relaciones humanas entre líderes y subordinados parecen influir en el emprendimiento individual más que colectivo o grupal por el simple hecho de incluir valores egocéntricos más que altruistas.

También se observan diferencias entre hombres y mujeres con respecto a situaciones de estrés en las que el espíritu emprendedor es inhibido más en los grupos masculinos que en los femeninos (Moreno, Ríos, Canto, García y Perles, 2010). Al parecer, las relaciones que se establecen entre hombres facilita el afrontamiento de ruido. 
Es en los grupos masculinos en donde se gesta un clima de confianza que se vincula más con la satisfacción de vida, principal indicador del espíritu emprendedor (Omar, 2010). A medida que las tareas implican la mayor coordinación se incrementa la colaboración entre los trabajadores, pero una reducción de la misma está más próxima a la frustración, aunque ello implica la innovación de ideas como otro síntoma del emprendedurismo.

Sin embargo, los acuerdos entre líderes parece afectar más la dinámica de trabajo entre los subordinados e incluso los motiva a llevar a cabo estrategias para ajustar sus acciones a las decisiones de los altos mandos (Yañez, Arenas y Ripoll, 2010). Ello significa que el espíritu emprendedor también estaría motivado por la dinámica de decisiones y sus efectos sobre la estabilidad laboral de los empleados.

Si la satisfacción laboral es el resultado de un clima de tareas y relaciones positivas, entonces el espíritu emprendedor tendría dos dimensiones. La primera dimensión sería el producto de contextos favorables a la formación de grupos así como a la consecución de objetivos mientras que la segunda sería el resultado de una serie de barreras y obstáculos desde las que se incentiva la creatividad y la innovación (Adenike, 2011).

Empero, si los resultados se alejan de las metas establecidas, entonces surgen una serie de conflictos que avizoran el cambio el cambio de paradigma en las relaciones interpersonales y el modo en que el trabajo en equipo se lleva a cabo (Celik, Turunc y Begenirbas, 2011).

En otros casos, el espíritu emprendedor al correlacionar espuriamente con la satisfacción de vida denota otros factores que le estarían influyendo ya que estaría más bien indicado por factores de orden impersonal y cercanos a niveles de estrés que lejos de aminorar el emprendedurismo lo acreditan como una alternativa ante contingencias organizacionales (Jyoti y Jyoti, 2011).

En referencia al desempeño y la productividad, ambas dimensiones del espíritu emprendedor anuncian la incorporación de estilos de vida que se desarrollan al interior de las organizaciones como respuesta a la ausencia de liderazgos (Rodríguez, Retamal, Lizana y Cortejo, 2011). Esto significa que cuando los canales de comunicación se encuentran bloqueados, entonces los empleados se adaptan a un patrón de producción que los lleva a conseguir las metas. Esto es así porque en ámbitos laborales está de por medio la estabilidad económica de talentos que, ante la embestida de problemáticas inherentes a la alta dirección o crisis de reconocimiento, desarrollan habilidades, conocimientos y valores orientados a la innovación de los procesos más que al control de calidad (Rojas, García \& García, 2011 ). El emprendimiento es bajo el contexto del conflicto una construcción de las necesidades, expectativas y competencias de empleados. 
Sin embargo, el espíritu emprendedor también subyace por el sentido de comunidad, arraigo e identidad en torno a una región, localidad o espacio (Yuangion, 2011). Es decir, los trabajadores que residen en las zonas aledañas a las organizaciones están dispuestos a aceptar las condiciones de trabajo mientras se generen empleos que favorezcan a la comunidad, aunque la empresa se lleve la mayor de las ganancias.

Son los procesos de identidad los que envuelven el emprendedurismo, pero también la competencia por los recursos. En ambos casos, el compromiso organizacionl se devela como un factor relevante al incidir sobre el desempeño, la satisfacción y las competencias (Anwar y Norulkamar, 2012).

En aquellas localidades en donde las trasnacionales implementaron sistemas de gestión de conocimiento y transfirieron a la comunidad un modelo de producción, el compromiso laboral se intensificó (Díaz, Hernández y Roldán, 2012). Esto es, se generó un conocimiento compartido, pero en los casos en donde el conocimiento fue el resultado de la techología de trasnacionales y la participación local comunitaria, el compromiso también se incrementó sustancialmente (Hallak, Brown y Lindsay, 2012). Los mismos procesos se observaron en aquellos casos en los que las empresas trasnacionales implementaron modelos de gestión de conocimiento en las pequeñas y medianas empresas locales (Hazlina, Mohd y Rohaida, 2012). El compromiso laboral parece haber sido el determinante principal del emprendedurismo siempre que la confianza y la innovación estuvieron correlacionadas con ambas variables (Tayo y Adeyemi, 2012).

A partir de tales revisiones es posible afirmar que el emprendedurismo tiene como indicadores esenciales al compromiso, confianza, innovación, cooperación y resilencia (Cardon, Gregoire, Stevens \& Patel, 2013; Danes y Joyoung, 2013). Al relacionarse con la cultura local, los usos y costumbres comunitarios así como con la identidad regional, el espíritu emprendedor incremento sustancialmente sus valores de satisfacción de vida (Rante y Warokka, 2013).

No obstante, la planificación estratégica a partir de estándares internacionales de calidad ha repercutido en una mayor productividad e intensificación de la competitividad más que los modelos híbridos y las alianzas entre trasnacionales y pymes (Zampetakis y Mostakis, 2013).

En síntesis, el estado de la cuestión advierte sobre la emergencia del emprendedurismo en contextos locales desde los que se gestan alianzas estratégicas a nivele regional y local en los que las comunidades adoptan sistemas de gestión, producción, logística y ventas diseminados por las trasnacionales a través de pymes o micro-empresas.

En un contexto en el que las políticas de fomento empresarial se intensifican, el espíritu emprendedor parece ser una respuesta de las comunidades que 
anteriormente eran migrantes y que ahora son escenarios de inversión federal y local que los adentró en una dinámica sobre la cual construyeron representaciones, habitus, campos, capitales y capacidades orientadas al desarrollo local.

\section{Consideraciones finales}

El emprendedurismo en un contexto de migración y comercialización de los recursos naturales en Xilitla está determinado por representaciones, habitus, campos y capitales desde los cuales se diseminan indicadores de confianza, compromiso, innovación, gestión, liderazgo, competitividad y desempeño. Una revisión de los estudios en torno a los determinantes del espíritu emprendedor confirma supuestos en torno a los cuales la resiliencia es un factor consustancial a su surgimiento cuando se gestan dinámicas estresantes en las que el agotamiento, despersonalización o frustración emergen como sus principales síntomas. Empero, el emprendedurismo subyace en contextos de arraigo e identidad los cuales son aprovechados por las trasnacionales al momento de establecer alianzas con pymes locales y cooperativas locales. En este sentido, las capacidades emprendedoras adquieren nuevas estrategias de producción, distribución y venta aprovechando redes de relaciones comunitarias.

Las representaciones sociales de las marcas globales parecen formar habitus de consumo desde los que se construyen campos discursivos de poder que dan valor a los productos y servicios trasnacionales a través de las organizaciones locales. en este proceso se compaginan los modelos de alianzas estratégicas con los recursos discursivos que se desarrollaron en las comunidades a partir de la entrada de multinacionales. Lejos de usurpar los recursos naturales, las trasnacionales aprovecharon los contextos discursivos para implementar modelos de negocios que se complementaron con el aprendizaje de los migrantes en su travesía por los EU.

De este modo, el emprendedurismo en Xilitla reduce las diferencias entre multinacionales y pymes locales para construir discursos en torno a la cooperación, compromiso e innovación plasmados en la producción de café orgánico y promoción ecoturista que hacen de Xilitla un pueblo mágico emprendedor.

El proceso que implicó la transformación de una localidad migrante a una comunidad comerciante significó el cambio de representaciones sociales el cuál consistía en símbolos de subsistencia fuera de la región. Una vez en los EU los migrantes aprendieron habitus de consumo que les influyó en sus decisiones de retornar a Xilitla para implementar los modelos de comercio aprendidos. Su llegada a Xilitla fue respaldada con campos discursivos en torno a los cuales ellos representaban el progreso para la comunidad no sólo 
en términos económicos, sino además en aspectos sociales. En ese sentido, la inversión de capital semilla se complemento con las políticas de fomento empresarial que el gobierno federal y local se encargaron de diseminar entre quienes podían valorar y utilizar responsablemente el capital encomendado. Por último, la llegada del capital extranjero complemento la dinámica emprendedora de Xilitla ya que permitió la construcción de infraestructura hotelera que potencializó a la comunidad como pueblo mágico, ecoturista y caficultor.

Sin embargo, está pendiente la explicación en torno a la relación entre trasnacionales y pymes ante sequías e inundaciones. En efecto, el cambio de clima parece ser la amenaza potencial de la región ya que sus actividades dependen directamente de la distribución equitativa del agua. Un desbalance en la asignación de agua entre trasnacionales, pymes y comunidades incidiría en los modelos de producción, distribución y venta.

La Teoría de la Fiabilidad Social (SRT por sus siglas en inglés) señala que a diferencia de los contextos de satisfacción de vida en los que la confianza y el compromiso son sus principales ejes, en un contexto de incertidumbre el emprendedurismo subyace como una respuesta solidaria ante la desgracia ecológica, económica o social. Precisamente, las representaciones, habitus, campos, capitales y capacidades emprendedoras en Xilitla parecen converger más con el modelo emprendedor de estabilidad en referencia al modelo de incertidumbre.

Es por ello fundamental promover la fiabilidad social entre los actores implicados en el desarrollo local de Xilitla. No obstante, la participación del gobierno local y federal ya no sólo se reduciría a la asignación de capital semilla, sino que ahora su función consistiría en la organización de una red de libertades, oportunidades, capacidades y responsabilidades traducidos a un sistema de gobernanza. La trasparencia en la asignación de recursos financieros no sería suficiente si ante una contingencia o catástrofe las autoridades procuraran el bienestar de un sector en detrimento de otro. Se requiere un sistema de gobierno en el que las decisiones ya no sean discrecionales y se ajusten a principios de Desarrollo Local Sustentable.

La gobernanza de los recursos naturales orientada al desarrólo local supone la construcción de una agenda pública en la que los temas centrales son relativos a la fiabilidad social y el emprendimiento.

El espíritu empresarial supone la implementación de políticas de fomento productivo en comunidades y localidades que establecen alianzas estratégicas con trasnacionales a través de pymes. Asimismo, es el resultado de un proceso de representación social en el que su núcleo central está conformado por valores, habilidades y conocimientos de emprendimiento transmitidos de generación en generación. Son las experiencias en su 
estancia como migrantes en los EU las que complementan las representaciones sociales y develan habitus heredados en Xilitla y adquiridos en EU.

Es en el habitus adquirido de donde se derivan campos discursivos de poder que hicieron líderes a los ex migrantes ya que se los considera por parte de la comunidad como ejemplos a seguir en cuanto a espíritu empresarial se refiere. Palabras tales como: "marketing", "business", "commitment" o "capabilities" han sido incorporados en la comunidad como símbolos de poder discursivo y significados de comercio. Aunado a los campos discursivos, la formación de microempresarios se llevó a cabo a partir de la confianza y la cooperación que se tradujeron en alianzas estratégicas de la comunidad para con trasnacionales.

En suma, la localidad de Xilitla adquirió las capacidades empresariales suficientes para promoverse como pueblo mágico, ecoturista y caficultor. Una vez que su imagen de migrante fue transformada en una imagen de comercio, la comunidad y sus autoridades están ante la posibilidad de enfrentar contingencias ambientales que trastoquen su desarrollo local.

\section{Referencias}

Adenike, A. (2011). Organization climate as a predictor of employee job satisfaction. Business Intelligence Journal. 4, 151-166

Anwar, F. y Norulkamar, U. (2012). Mediating role of organizational commitment among leadership and employee outcomes, and empirical evidence from telecom sector. Processing International Seminar on Industrial Engineering and Management 2, 116-161

Arnau, L. y Montané, J. (2010). Aportaciones sobre la relación conceptual entre actitud y competencia, desde la teoría del cambio de actitudes. Journal of Research in Educational Psychology. 8, 1283-1302

Basta, R., Cavalleri, M., Fink, T., López, X., Maiola, F., Stancanelli, M., y Vdovsov, L. (2012). Una aproximación a la producción teórico metodológica de Pierre Bourdieau. Su influencia en el Trabajo Social Argentino. Plaza Pública, 8, 39-51

Berdecia, Z., González, J. y Carrasquillo, C. (2012). Estilos de liderazgo para el éxito organizacional: estudios de casos múltiples en empresas. Revista de Estudios Avanzados de Liderazgo, 1, 21-32 
Borjas, L. (2010). El espíritu empresarial desde las representaciones sociales: caso Venezuela. Ciencias Sociales, 5, 149-165

Bourdieu, P. (201 1). Las estrategias de reproducción social. México: Siglo XXI Capdevielle, J. (2011). El concepto de habitus. Anduli. Revista Andaluza de Ciencias Sociales, 10, 31-45

Cardon, M., Gregoire, D., Stevens, C. y Patel, P. (2013). Measuring entrepreneurial passion: conceptual foundations and scale validation. Journal of Business Yenturing, 28, 373-396

Castel, G. y Freundlich, F. (2010). Percepciones de los socios y no socios cooperativista sobre la satisfacción laboral. Revesco. 103, 33-58

Castro, M. (2011). Habitus lingüístico y derecho a la información en el campo médico. Revista Mexicana de Sociología, 73, 231-259

Castro, M. y Martins, M. (2010). The relationships between organizational climate and employee satisfaction in information and technology organization. Tydskriff vir Bredyfsielkunde. 36, 1-9

Caykoylu, S., Egri, C., Havlovic, S. y Bradley, C. (2011). Key organizational commitment antecedents for nurses, paramedical professionals and nonclinical staff. Journal of Health Organization and Management. 25, 7-33

Celik, M., Turunc, O. y Begenirbas, M. (2011). The role of organizational trust, Burnout and interpersonal deviance for achieving organizational performance. International Journal of Business and Management Studies. 3, $179-190$

Chiang, M., Méndez, G. y Sánchez, G. (2010). Cómo influye la satisfacción laboral sobre el desempeño: caso empresa de reatail. Revista Theoria. 19, $21-36$

Chinchilla, N. y Cruz, H. (2010). Diversidad y paradigmas de empresa: un nuevo enfoque. Revista Empresa y Humanismo, 14, 47-79

Coronel, A. (2010). Capacitación del capital humano para una inversión de desarrollo. Eureka, 7, 71-76

Cuesta, A. (2012). Modelo integrado de gestión humana y del conocimiento: una tecnología de aplicación. Revista Venezolana de Gerencia, 57, 86-98

Danes, S. y Juyoung, J. (2013). Copreneural identity development during new venture creation. Journal of Family Business Management, 3, 45-61

Díaz, C., Hernández, R. y Roldán, J. (2012). A structural model of the antecedents to entrepreneurial capacity. International Small Business Journal, 30, 850-872 
Díaz, S. (2013). Lo humano en la Teoría de las Organizaciones. Visión gerencial, 12, 45-57

Figeiredo, H., Grau, E., Gil, P. y García, J. (2012). Síndrome de quemarse por el trabajo y satisfacción laboral en profesionales de enfermería. Psocthema, $24,271-276$

Fortich, M. y Moreno, Á. (2012). Elementos de la teoría de los campos. Verba Iuris, 27, 47-62

Fuentes, F. y Sánchez, S. (2010). Análisis del perfil emprendedor: una perspectiva de género. Estudios de Economía Aplicada, 28, 1-28

Galindo, R. y Echavarría, M. (2011). Diagnóstico de la cultura emprendedora en la escuela de ingeniería de Antioquia. Revista de la Escuela de Ingeniería de Antioquia, 15, 85-94

García, A. (2011). Micro conflictos espaciales y habitus político de los grupos contra hegemónicos. Nomadas, 3, 1-20

García, C., Quintero, M. L., Carreón, J., Rincón, R. M., Sánchez, A., Fierro, E. (2019). Redes formativas inteligentes en una universidad pública del centro de México. Epsys, 12 (1), 1-14

Gargallo, A. (2010). Percepciones de los socios y no socios cooperativistas sobre la satisfacción laboral. Revesco, 103, 33-58

Gaxiola, J., Frías, M., Hurtado, M., Salcido, L. y Figueroa, M. (201 1). Validación del inventario de resiliencia (IRES) en una muestra del noreste de México. Enseñanza e Investigación en Psicología. 16, 73-83

Giddens, A. (2011). La constitución de la sociedad. Bases para la Teoría de la Reestructuración. Buenos Aires: Amorrortu Editores.

González, E. y Pérez, E. (2012). Condiciones laborales y desgaste profesional en trabajadores de salud. Alternativas en Psicología, 27, 8-22

González, F., Sánchez, S. y López, T. (2011). Satisfacción laboral como factor crítico para la calidad. Estudios y Perspectivas en Turismo, 20, 1047-1068

Guillén, M. Lleó, A. y Perles, G. (2011). Repensando la confianza como factor crítico en la gestión organizativa. Cuadernos de Gestión. 11. 33-47

Hallak, R., Brown, G. y Lindsay, N. (2012). The place identity performance relationships among tourism entrepreneurs: a structural equation modeling analysis. Tourism Management, 33, 143-154

Hazlina, N., Mohd, A. y Rohaida, S. (2012). Nurturing intrapreneurship to enhance job performance: the role of pro-intrapreneurship organizational architecture. Journal of Innovation Management in Small \& Medium Entreprises, , 9, 1-9 
Joignant, A. (2012). Habitus, campo y capital. Elementos para una teoría general del capital político. Revista Mexicana de Sociología, 74, 587-618

Jyoti, J. y Jyoti S. (2011). Factors affecting orientation and satisfaction of women entrepreneurs in rural India. Annals of Innovation Entrepreneurships, $2,1-8$

Lanier, J. (2012). Leadership and organizational theory dynamics between middle market private equity forms and the portfolio companies they control. Journal of Practical Consulting, 4, 6-21

Long, H. (2013). The relationships among learning orientation, market orientation, entrepreneurial orientation, and firm performance. Management Review, 20, 37-46

López, A., Vázquez, P. y Montes, C. (2010). Mobbing: antecedentes psicosociales y consecuencias sobre la satisfacción laboral. Revista Latinoamericana de Psicología, 42, 215-224

Manning, A. (2010). Development of the psychological climate scale for small business. Journal of New Business Ideas \& Trends. 8, 50-63

Martínez, E. (2013). Cabilia: la problemática génesis del concepto de habitus. Revista Mexicana de Sociología, 75, 125-131

Mejía, S., Carreón, J., García, C., Quezada, A., Martínez, M., López, S., Hernández, J. y Morales, M. L. (2019). Estructura factorial exploratoria de la percepción y disposición hacia la seguridad. Epsys, 28, 1-6

Mendoza, M., Orgambídez, A. y Carrasco, A. (2010). Orientación de la calidad total, satisfacción laboral, comunicación y compromiso en establecimientos de turismo rural. Revista de Turismo y Patrimonio Cultural. 8, 351-361

Molero, F., Recio, P., y Cuadrado, I. (2010). Liderazgo transformacional y transaccional: un análisis de la estructura factorial del multifactor Leardership Questionaire (MLQ). Psicothema. 22, 495-501

Morales, A., Ariza, A. y Muñiz, N. (2012). El emprendedor social y eempowerment de las redes sociales. Revista de Economía Pública, Social y Cooperativa, 75, 152-177

Moreno, M., Ríos, L., Canto, J., García, J. y Perles, F. (2010). Satisfacción laboral y Burnout en trabajos poco cualificados: diferencias entre sexos en población inmigrante. Revista de Psicología del Trabajo y las Organizaciones, 26, 255-265

Omar, A. (2010). Liderazgo transformador y satisfacción laboral: el rol de la confianza en el supervisor. Liberabit. 17, 129-137 
Rante, Y. y Warokka, A. (2013). The interrelative nexus of indigenous economic growth and small business development: do local culture, government role, and entrepreneurial behavior play the role? Journal of Innovation Management in Small \& Medium Enterprises. 19, 1-19

Ríos, M., Téllez, M. y Ferrer, J. (2010). El empoderamiento como predictor del compromiso organizacional en las pymes. Contaduría y Administración. 231, 103-125

Rodríguez, A., Retamal, R., Lizana, J. y Cornejo, F. (2011). Clima y satisfacción laboral como predictores del desempeño: en una organización estatal chilena. Salud y Sociedad. 2, 219-234

Rojas, R., García, V. y García, E. (2011). The influence on corporate entrepreneurship of technological variables. Industrial management \& Data System, 111, 984-1005

Rosas, F. J., Gómez, D. A. y García, C. (2019). Especificación de un modelo para el estudio de la percepción de movilidad. Eureka, 16 (1), 177-188

Sen, A. (2011). The idea of justice. Cambridge: Harvard University Press

Sobrados, L. Y Fernández, E. (2010). Competencias emprendedoras y desarrollo del espíritu empresarial en los centros educativos. Educación XXI, $13,15-38$

Tayo, E. y Adeyemi, A. (2012). Job involvement \& organizational commitment as determinants of job performance among educational resource centre personal. European Journal of Globalization and Development Research. 5, 301-313

Vargas, J. (2011). Organización del trabajo y satisfacción laboral: un estudio de caso en la industria del calzado. Revista Electrónica Nova Scientia. 4, 172204

Vargas, J. (2013). Las organizaciones como cerebros para generar capital social. International Journal of Good Conscience, 8, 82-93

Vargas, J. y Mota, C. (2013). Gerencia social para la equidad de género en las organizaciones. International Journal of Good Conciensus, 8, 130-47

Vargas, M. y Arenas, M. (2012). Competencias emprendedoras en estudiantes de psicopedagogía de la Universidad Pedagógica y Tecnológica de Colombia. Revista de Estudios Avanzados de Liderazgo, 1, 25-30

Vera, L., Madrazo, S. y García, L. (2011). Fuentes de satisfacción laboral en campesinos asalariados jóvenes. Revista Concyteg. 77, 1281-1306 
Villegas, E., Sánchez, A., Espinoza, F., García, C. y Quintero, M. L. (2019). Estructura factorial exploratoria de capital humano intelectual. Foro Educacional, 32, 31-51

Yáñez, R., Arenas, M. y Ripoll, M. (2010). El impacto de las relaciones interpersonales en la satisfacción laboral. Liberabit. 16, 193-202

Yuangion, Y. (2011). The impact of strong ties on entrepreneurial intention. An empirical study based on the mediating role of self-efficacy. Journal Entrepreneurship, 3, 147-158

Zampetakis, L. y Moustakis, V. (2013). Entrepreneurial behavior in the Grekk public sector. Emerald, 13, 1-7

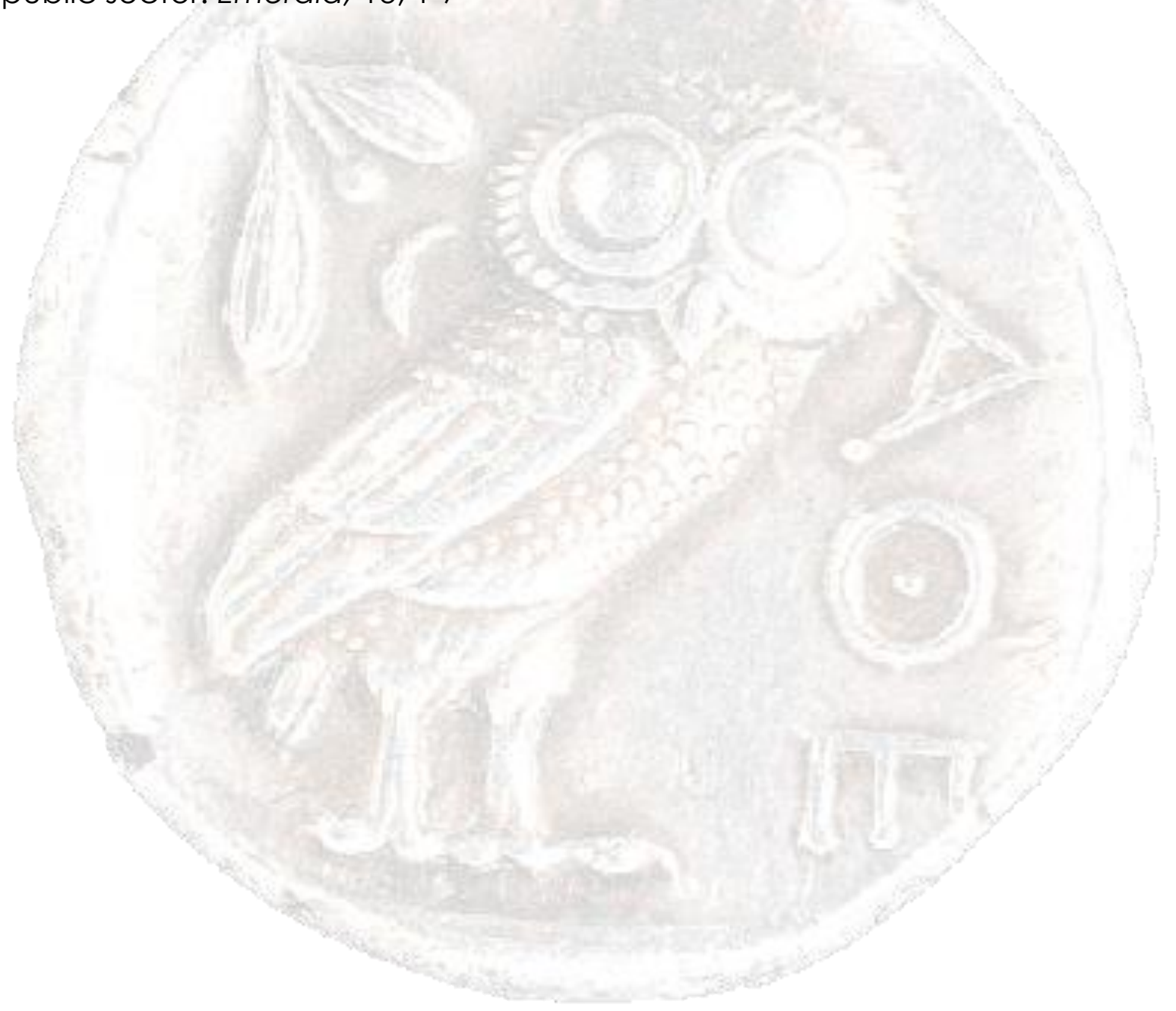

